\title{
Perforation Of The Small Intestine Due To Thoracic Gunshot Injury
}

\author{
Gökhan KILINÇ*, Bülent ATiK*, Sümeyye KILINÇ**, Aslı Akcan Atasoy* \\ * Department of Anesthesiology and Reanimation, Balikesir Atatürk City Hospital, Balikesir, Turkey \\ **Department of Anesthesiology and Reanimation, Faculty of Medicine, BalikesirUniversity, Balikesir, \\ Turkey \\ doi.org/10.33706/jemcr.544517
}

\begin{abstract}
Introduction: Gunshot wounds can cause life-threatening injuries because they are high-energy traumas. Even gunshot or rifle injuries to the penetrating extraperitoneal abdomen or chest wall can cause damage to the abdominal organs despite a robust peritoneum and diaphragm. There are two different injury mechanisms resulting from gunshot wounds. These are related to the "crushing" and "stretching of the tissues. Penetration and permanent cavity effects are generally visible in injuries with projectiles. The other major impacts, especially the temporary cavity, are difficult to show and are not known. In high-kinetic energy injuries, the temporary cavity is the main cause of the major damage caused by the bullet. There are more dangerous and more insidious effects than all of these, which is to create damage to the vascular endothelium.
\end{abstract}

Case Report: In this case, the organ that feeds into this vein can no longer be fed and goes to necrosis. Delayed perforation of the colon may occur within 72 hours after trauma. Gunshot wounds can cause serious injury. The organs near the projectile can be injured. Caution should be exercised for the possibility of indirect ballistic injury away from the projectile direction. Monitoring and grading of these important injuries is very important in terms of mortality and morbidity.

Conclusion: We aimed to present a 19-year-old patient who had bowel perforation after a thoracic gunshot wound.

Keywords: Gunshot, thoracal injury, intestinal perforation, trauma

\section{Introduction}

Gunshot wounds can cause life-threatening injuries because they are high-energy traumas. Even gunshot or rifle injuries to the penetrating extraperitoneal abdomen or chest wall can cause damage to the abdominal organs despite a robust peritoneum and diaphragm. Delayed or overlooked diagnoses of exploded intestinal injuries are often associated with high morbidity and mortality rates (1). One of the points that should not be forgotten in Toraksa nausea gunshot wounds is that the blast effect of the projectile can cause injuries to the abdominal organs, especially the liver, located below the diaphragm and just below it. In order for this type of injury to occur, the bullet does not need to penetrate these organs directly. The pressure waves of the transient cavity in the organs having a lot of blood parenchyma like liver spleen and kidney are easily transmitted because the fluids are well conductive and the damage caused by the temporary cavity in these organs is large (2).

\section{Case Report}


A 19-year-old male patient was brought to the emergency department with a gunshot wound. In the examination of the patient, the arterial blood pressure was $128 / 72 \mathrm{~mm} / \mathrm{Hg}$, pulse was 110 beats / minute spo2: 98, conscious, oriented, cooperative; abdominal examination was normal. At the left side of the sternum, there was a bullet entry hole and a bullet outlet hole in the right axillary region. Left hand wrist, left knee, right upper leg had bullet entry and exit holes. Right thorax tube was inserted to the patient with hemothorax and contusion area in the right lung. In the computed tomography of the patient, there is a defect on the anterior and lateral sides of the skin in the right hemithorax wall and air images under the skin. Contusion area was observed in the parenchyma of the right lung. Pneumothorax and hemothorax were observed in the right hemithorax. A clavicle fracture was observed on the left side. Bone fractures were seen in the middle zone in the right hemithorax. Abdominal CT of the patient was reported as normal. The patient was admitted to the intensive care unit. Examination of the patient 8 hours later revealed no pathological findings. After 16 hours the general condition of the patient deteriorated, his breathing began to deteriorate. The patient was intubated. $\mathrm{He}$ was immediately referred to abdominal ultrasonography, chest X-ray, thoracic surgery, and general surgery consultation. A large amount of liquid containing intense fluid was detected in all compartments in the abdomen at USG. The patient received a noradrenaline infusion at a dose of $0.1 \mathrm{mcg} /$ $\mathrm{kg} / \mathrm{min}$. The patient was operated by general surgery when it became suitable for transport. During the operation, two perforations were observed on the anterior and posterior sides of the stomach, 4 perforations on the jejenum, $0.5 \mathrm{~cm}$ perforation on the gallbladder corpus and 1 perforation on the anterior wall in the descending colon sigmoid junction.

After all the perforations were repaired, the operation was terminated and the patient was taken to the intensive care unit. After the operation The patient's general condition was poor. The patient continued to receive inotropic support. Pulse: 138 beats per minute, blood pressure was 76/42 mm / Hg. At the 28th hour of his admission to the intensive care unit, the patient developed cardiac arrest. The patient underwent cardiopulmonary ressusitation for 60 minutes. The patient who was not responding to CPR was accepted as exitus.

\section{Discussion}

There are two different injury mechanisms resulting from gunshot wounds. These are related to the "crushing" and "stretching of the tissues. The crushing mechanism is related to the passage of the projectile through the tissues, the tissues being pushed out of the centrifuge and this results in permanent space. The tensioning mechanism applies to adjacent tissues and may be equivalent to the transient space formed when the bullet passes through the tissues. The transient gap reaches four atmospheric pressures of about 4-5 milliseconds. The temporary space can injure the blood vessels and fracture bones not passing directly by the projectile, and as the energy transfer of the projectile increases, the temporary space produced grows (3). Elastic tissues with more flexibility, such as the lung and intestine wall, tolerate this tension better. Non-elastic solid organs, such as the liver, cannot tolerate well (4).

Penetration and permanent cavity effects are generally visible in injuries with projectiles. The other major impacts, especially the temporary cavity, are difficult to show and are not known. Penetration is directly related to the kinetic energy and shape of the projectile. As the tip gets tapered and harder and the kinetic energy increases, the penetration power increases. Permanent wound cavity is a concept related to the diameter of the bullet. When the bullet enters the tissue, it creates a permanent wound path in proportion to its size and can be demonstrated by autopsy, surgery and radiological methods (5).

In high-kinetic energy injuries, the temporary cavity is the main cause of the major damage caused by the bullet. This cavity cannot be shown in static studies and can only be viewed as soon as it occurs (6).

When the energy with a very high energy that exceeds the sound velocity starts to tumble in the body and rotates 90 degrees, the energy transfer becomes maximum and this kinetic 
energy transmitted to the environment in a very short time creates a blast effect and a very rapid translational motion in the surrounding tissues. The tissues remaining in this temporary cavity are damaged and destroyed according to their elasticity and resistance. Then, when the bullet continues to parallel with the bullet path, this transfer decreases and the diameter of the cavity decreases. If the target depth is sufficient, the bullet will continue to tumble and throw the 2nd and 3rd takings and create the 2nd and 3rd cavities. That is why thoracoabdominal injuries with a longer target depth are more fatal since multiple transient cavities may occur as well as two cavities being affected $(5,6)$.

Deformation and fragmentation occurs if the bullet hits the bone within the target or passes through a hard intermediate target without entering the target (6). The deformation increases the friction surface with both the change of shape and causes the projectile to change early by changing the ballistic properties of the projectile. In this case, the ability of the projectile to transfer energy is increased much more than expected (7)

There are more dangerous and more insidious effects than all of these, which is to create damage to the vascular endothelium. A vessel that feeds any organ is not affected directly by the bullet during the passage, but is affected by this phenomenon if it remains in the temporary cavity. When the blast effect is shifted very rapidly by the vessel, or when the vein is directly shifted by the blast effect, an elongation in the length of the vessel within a few milliseconds and then shortening becomes the old longitudinal rotation. Since the media and adventitia layers of the vein are composed of very strong and elastic fibers, this sudden extension is adapted to the shortening movement. However, the intima layer laying inside the vein cannot adapt to this shortening. In these tears, platelet aggregation develops over time, or the blood flow enters the intima and delays it and causes a valve formation. The sutures and anastomoses which are evaluated as live in the first operation and then thrown into these tissues which are necrosis are thus at serious risk. This is one of the most common causes of delayed anastomosis and repair leaks (8).
The availability and use of computed tomography (CT) resulted in a paradigm shift in managing penetrating trauma. CT provides preoperative diagnosis. This provides valuable information to the surgeon in planning the treatment approach. CT shows the presence of intact visceral injuries reliably and allows these injuries to be graded. However, it should always be noted that there is a possibility of indirect injury, especially with a weapon (9).

Delayed perforation of the colon may occur within 72 hours after trauma. Therefore, patients who are exposed to significant explosive explosions, especially those with other injuries requiring analgesics, should be carefully monitored for at least 48 to 72 hours. Along with careful clinical observations, relevant diagnostic tests such as CT studies, sonography, diagnostic peritoneal lavage, laparoscopy and even laparotomy may also be mentioned. It is essential to perform bowel trauma at the time of surgery (10).

\section{Conclusion}

Gunshot wounds can cause serious injury. The organs near the projectile can be injured. These injuries can be found even in an adjacent cavity that does not directly pass by the lead. Caution should be exercised for the possibility of indirect ballistic injury away from the projectile direction. Monitoring and grading of these important injuries is very important in terms of mortality and morbidity.

\section{References}

1.Bounovas A, Perente S, Laftsidis P, Polychronidis A, Simopoulos C. Perforation of the colon from the primary blast effect of an extraperitoneal shotgun injury: case report. Military medicine. 2007;172(3):327-8.

2.Çaylak H, Genç O. Toraksı ilgilendiren ateşli silah yaralanmaları. Bulletin of Thoracic Surgery/Toraks Cerrahisi Bülteni. 2010;1(1):29-32.

3.Fackler ML, Malinowski JA. The wound profile: a visual method for quantifying gunshot wound components. The Journal of trauma. 1985;25(6):522-9.

4.Sardiwalla I, Govender M, Matsevych O, Koto MZ. Indirect ballistic injury to the liver: Case report and review of literature. International Journal of Surgery Open. 2016;5:236.

5.Uzar Ai, Güleç B, Kayahan C, Özer MT, Öner K, Alpaslan F. Wound ballistics - $\mathrm{i}$ effects of permanent and temporary wound cavities. Ulus Travma Acil Cerrahi Derg. 1998;4:2259.

6.Özer MT, Öğünç G, Eryılmaz M, Yiğit T, Menteş MÖ, Dakak $M$, et al. Organ models in wound balistics: experimental study. Turkish Journal of Trauma and Emergency Surgery. 2007;13(1):20-7. 
7.Uzar AI, Dakak M, Oner K, Atesalp AS, Yigit T, Ozer T, et al. Comparison of soft tissue and bone injuries caused by handgun or rifle bullets: an experimental study Acta Orthop Traumatol Turc. 2003;37(3):261-7.

8.Özer MT. Wound Ballistic of Gunshot Injuries with High Kinetic Energy and Reflections to the Surgical Treatment. Eur Arch Med Res. 2017;33(0):40-7.

9.Múnera F, Morales C, Soto JA, Garcia HI, Suarez T, Garcia V, et al. Gunshot wounds of abdomen: evaluation of stable patients with triple-contrast helical CT. Radiology. 2004;231(2):399-405.

10.Bounovas A, Perente S, Laftsidis P, Polychronidis A, Simopoulos C. Perforation of the colon from the primary blast effect of an extraperitoneal shotgun injury: case report. Military medicine. 2007;172(3):327-8.

\section{Funding: None Declared}

\section{Conflict of Interest: None Declared}

Corresponding Author: Gökhan Kılınç

Department of Anesthesiology and Reanimation, Balikesir Atatürk City Hospital, Balikesir, Turkey

e-mail: gkilinc35@hotmail.com 